\title{
Application of six sigma DMAIC methodology to reduce service resolution time in a service organization
}

\author{
Virender Narula ${ }^{a, b^{*}}$ and Sandeep Grover
}

${ }^{a}$ Research Scholar, Mechanical Engineering, Y M C A US T, Faridabad 121006, India

${ }^{b}$ Associate Professor, Faculty of Engineering \& Technology, Manav Rachna International University, Faridabad, India

${ }^{c}$ Professor \& Dean - Engineering and Technology YM C A University of Science and Technology Faridabad

CHRONICLE ABS TRACT

Article history:

Received June 5, 2015

Received in revised format August 162015

Accepted November 232015

Available online

November 252015

Keywords:

Process variation

Common causes

Special causes

Control charts

\begin{abstract}
The popularity of Six Sigma, as a means for improving quality, has grown exponentially in recent years. It is a proven methodology to achieve breakthrough improvement in process performance that generates significant savings to bottom line of an organization. This paper illustrates how Six Sigma methodology may be used to improve service processes. The purpose of this paper is to develop Six Sigma DMAIC methodologies that would help service organizations look into their processes. In addition, it demonstrates the vital linkages between process improvement and process variation. The study identifies critical process parameters and suggests a team structure for Six Sigma project in service operations.
\end{abstract}

(C) 2015 Growing Science Ltd. All rights reserved.

\section{Introduction}

Service operations comprise $80 \%$ of GDP in United States and are rapidly growing around the world. In Indian economy also, service sector accounts for substantial share of GDP (Besseris, 2013). The cost associated with work that adds no value in customers' eyes is typically $50 \%$ of total service expenses. It means there is enormous potential for achieving improvements in service operations (Levin $\&$ Rubin, 1999). In addition, service quality is a priority for organizations that wish to differentiate their services. To meet and exceed customers' expectations, service organization must deliver services with capable processes. For delivering high quality services at competitive prices, it is necessary to completely understand the process and how the variation in various process parameters influences on the process output. In addition, knowledge about process control and statistical methods and expected benefits by implementing Six Sigma Methodology is significant to achieve process improvement. Six Sigma for service operations is a business improvement methodology that maximizes shareholder value by achieving the fastest rate of improvement in customer satisfaction, cost, quality and service time. * Corresponding author.

E-mail address: virender.narula@gmail.com (V. Narula) 
According to Hoerl and Snee (2012), "Six Sigma is a statistically based quality improvement program that helps to improve business processes by in waste and costs resulting from poor quality and by improving levels of efficiency and effectiveness of the process".

This paper is organized in four sections. First, literature review of Six Sigma initiatives in services is presented. Section 3 presents a case study of Six Sigma, which includes define measure, analyze, improve and control (DMAIC) methodology in a service organization. Finally, the paper ends with conclusion drawn based on the case study.

\section{Literature review}

Sigma is a Greek letter representing variation in the process. Six Sigma is a scientific methodology to reduce the number of defects as low as 3.4 defects per million opportunities (DPMO) in any process. It is a business strategy that has been well recognised as an imperative for operation and business excellence. According to Harry and Schroeder (2005), "Six Sigma is scientific method of collecting rigorous data and robust statistical analysis to pin point source of error and ways of eliminating them". Six Sigma is a formal methodology for defining, measuring, analyzing, improving, and then controlling or "locking-in" processes. The numerical goal of Six Sigma project is to reduce the occurrence of defects to Six Sigma level of defects i.e. 3.4 DPMO (Kumaravadivel \& Natarajan, 2013). Chakraborty and Kay Chuan (2009) presented issues highlighted by service industries during Six Sigma implementation through questionnaire survey. The authors presented empirical research through surveys to understand issues involving Six Sigma implementation in service organizations. Heckl et al. (2010) conducted a comprehensive survey in banks, insurance companies and related service providers in Germany and other European countries and found that desire to exploit market opportunities, pressure to reduce market cost and dissatisfied customers are the main drivers of Six Sigma projects. The authors presented the result of their survey to analyze acceptance level of Six Sigma methodology within financial services industry (Montgomery, 2009).

Chakraborty and Kay Chuan (2013) performed qualitative/quantitative analysis of Six Sigma organizations in Singapore and found out that application of Six Sigma in service sector was concentrated in a few services. They provided parameters to be considered for successful implementation of six sigma. The survey shows that $23 \%$ of responses were not aware of Six Sigma methodology, $23 \%$ found it not relevant or some them were not interested, time consuming and difficult in identifying process parameters. Lall and Gupta (2010) proposed define-measure-analyze-improvecontrol methodology for service organization. They further analyzed relevant Six-sigma tools for service industry and emphasized that Six Sigma methodology could be the next logical step for achieving improvement in customer service. Nakhai and Neves (2009) found that extreme drive for adopting Six Sigma in service organizations could lead both to limited field of application \& unrealistic expectation to what Six Sigma is truly capable of achieving particularly on service organizations. They provided the application of Six Sigma in various service sectors like financial services, healthcare, education, construction, utility and government offices. They also presented the service quality model and described the gap between Six Sigma and service quality. Natarajan and Morse (2009) identified challenges in implementing Six Sigma to a core service process and recommended the use of information technology as powerful enabler for implementing Six Sigma methodologies. Banuelas et al. (2006) used the survey as a method to investigate that what criteria is to be considered to select Six Sigma project and how potential projects are identified. They concluded that Six Sigma converts quality improvements into bottom line financial benefits and project selection is a key factor to success.

\section{Six sigma}

Service resolution time is one of the most significant dimensions of quality of a service process. The present case study deals with reducing service resolution time for a customer queries process in a service organization (Chang \& Wang, 2008). The organization was doing a poor job towards resolution 
of customer quarries. The repeated customer complaints and dissatisfactions were causing a financial loss of rupees 10 lacs every year for the organization. To identify Critical to Quality Characteristics (CTQs), a questionnaire survey was conducted among concerned people in the organization. The questionnaire consists of focused 20 CTQs observed from cause and effect diagram. The questionnaire was reviewed by experts having substantial knowledge of implementing quality initiatives in service organizations. The questionnaire was designed on the pattern of Likert type scale from one to four in which, four represented the most significant and one was associated with the least significant. CTQs identified from survey were service resolution time, level of expertise, system down time, system reliability, and accuracy of information are presented in Fig. 2. Service resolution time was the most critical among all CTQs. Hence it was taken as Problem of Six Sigma project. The goal statement of problem was to reduce mean service resolution time by $25 \%$ which was approximately 10 hours. The project team includes a champion, a black belt, two green belts, process owner, and one management trainee. A snap shot representing high level process map for entire approach is shown in Fig. 1.

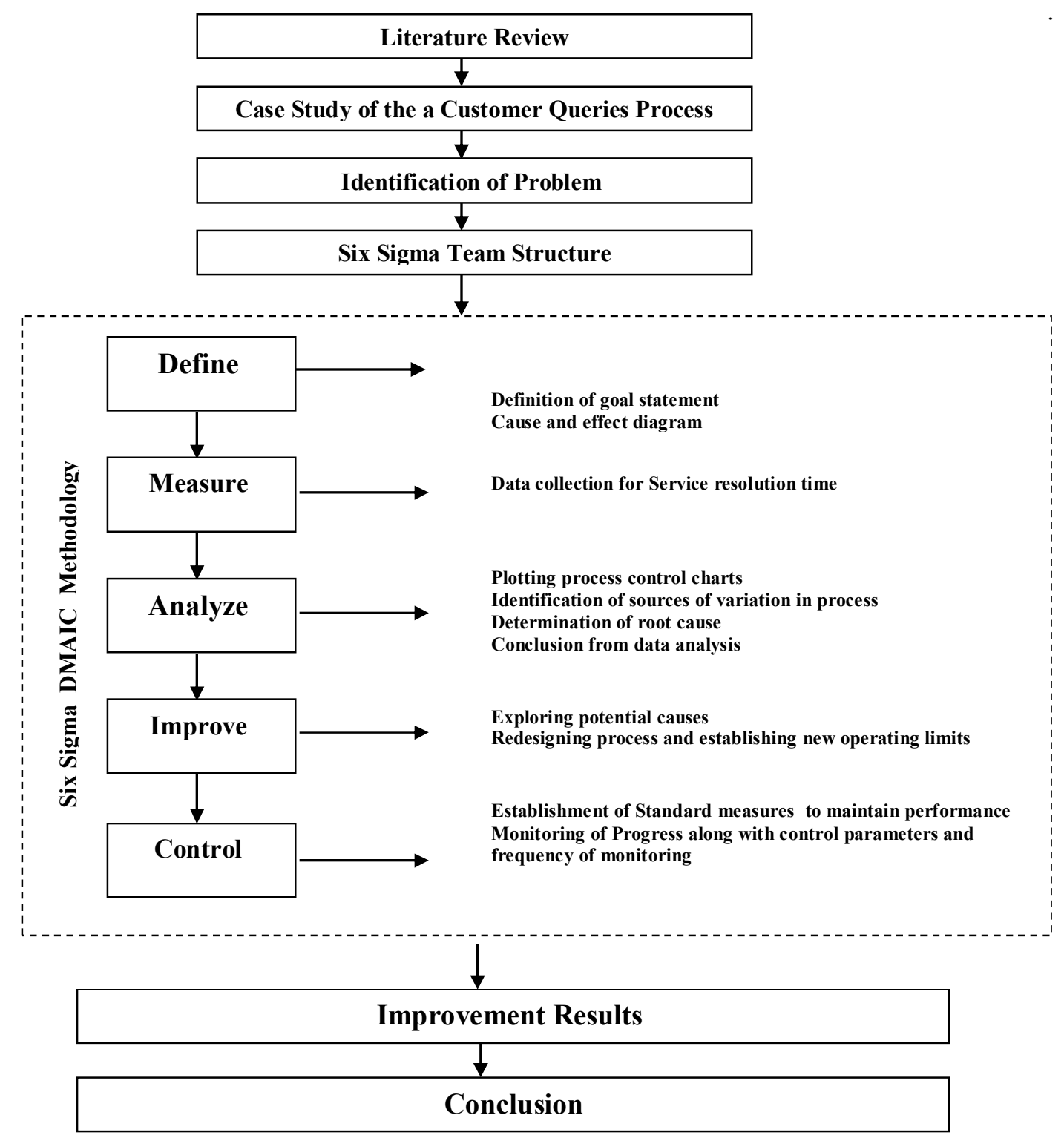

Fig. 1. High level process map for entire approach 


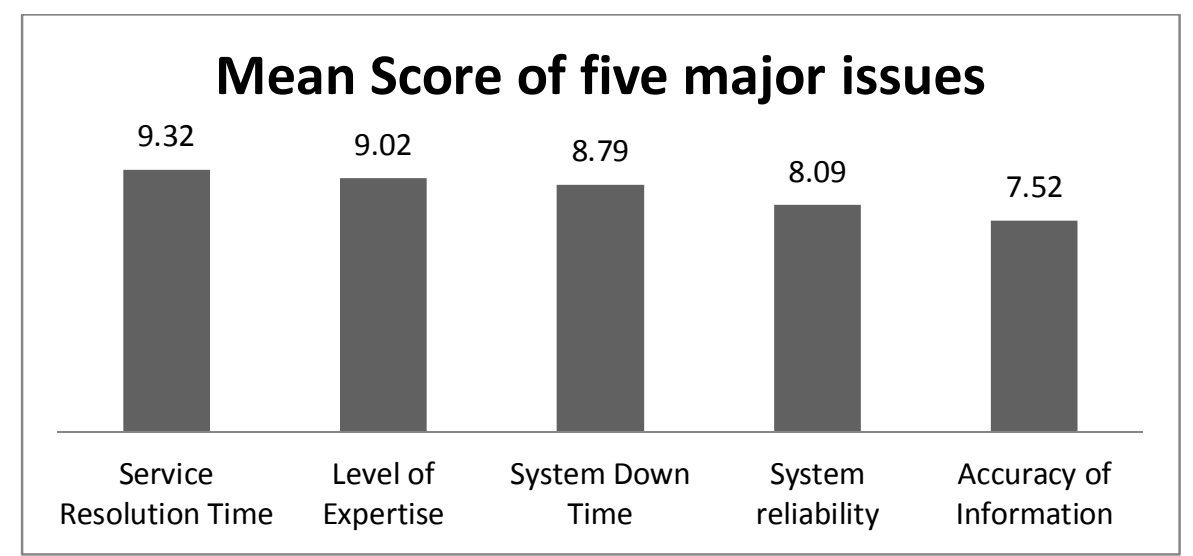

Fig. 2. Mean score of five major issues

\subsection{Define}

In define phase of Six-sigma, project team defines project suitable for Six Sigma efforts based on critical to quality characteristics. Project team also defines who the customers are, their priorities and the critical issues on quality for customers. While defining the problem, it is strongly recommended to describe only the effects not causes. It is also essential to scope the problem i.e. what are the boundaries and the constraints in which project is to be completed. Antony $(2000,2006)$ stated that the tools and techniques applicable for service organizations in define phase are process mapping, SIPOC, quality function deployment, project charter, calculations for cost of poor quality. In the present study, Six Sigma team had brain storming sessions with process owner and concerned people, and cause \& effect diagram (Fig. 3) was drawn with causes identified as personnel, method, measurement, material, machine and environment.

\subsection{Measure}

In measure phase, it is measured how the process is performing. In addition it is determined that what to measure and, how to measure. In present study, it was decided to collect data for service resolution time for four weeks ( 20 days) so that data could be analyzed further.

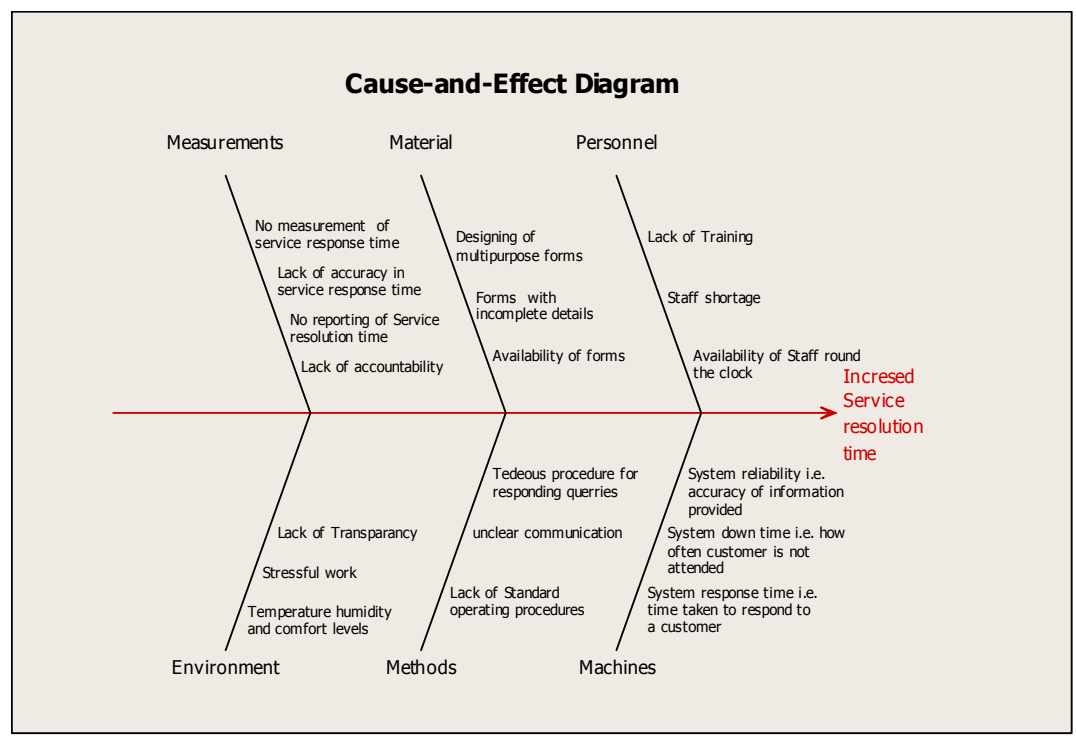

Fig. 3. Cause \& effect diagram 


\subsection{Analyze}

In Analyze phase, it was decided to plot $\mathrm{X}$ bar and $\mathrm{R}$ chart for service resolution time. The service resolution time was to be plotted in such a way that we could recognize common cause variation and assignable cause variation in data. When process is with in statistical control, only common causes are present and process exhibit random pattern. In case of X bar and $\mathrm{R}$ chart, it is desirable that process shift from mean be detected by $\mathrm{x}$ bar chart and $\mathrm{R}$ bar should capture only common cause variation. That means that there should be high probability of variation between subgroups and variation with in subgroup is minimum. For achieving this goal, the time difference with in a subgroup is minimum and time between subgroups is maximum i.e. next subgroups are chosen somewhat later so that any shift in process mean that have occurred will be displayed on the control chart as between subgroup variation. In the present work, average service resolution time was 10 hours. In the given data, a value of $n$ is six and $k$ are 20, respectively where, $n$ represents the number of observations in each subgroup and $k$ is the number of subgroups. In case of control charts it is customary to estimate the $\sigma$ on the basis of subgroup range $R$ and a constant $\mathrm{d} 2$ where $\mathrm{d} 2$ depends on subgroup size. The relationship between average of subgroup range and estimate of $\sigma$ is $\mathrm{R} \mathrm{bar/d}$. Now upper control limit and lower control limits of may be calculated as X bar \pm A2 $\times \mathrm{R}$ bar (Leavenworth \& Grant, 2000).

Table 3

Service Resolution time for Customer Queries Process

\begin{tabular}{|c|c|c|c|c|c|c|c|c|c|}
\hline \multirow{2}{*}{$\begin{array}{l}\begin{array}{l}\text { Subgroup } \\
\text { number }\end{array} \\
\text { Subgroup 1 }\end{array}$} & \multirow{2}{*}{$\begin{array}{l}\text { Day of the } \\
\text { week } \\
\text { Tuesday }\end{array}$} & \multicolumn{6}{|c|}{ Service resolution time in hours } & \multirow{2}{*}{$\begin{array}{l}\text { Subgroup mean } \mathrm{x} \\
\text { bar } \\
10.5\end{array}$} & \multirow{2}{*}{$\begin{array}{c}\begin{array}{c}\text { Subgroup } \\
\text { range } \mathrm{R}\end{array} \\
1.8\end{array}$} \\
\hline & & 11.2 & 10 & 10 & 9.5 & 10.8 & 11.3 & & \\
\hline Subgroup 2 & Wednesday & 10.7 & 11.2 & 10.7 & 11.7 & 11.2 & 11.8 & 11.2 & 1.1 \\
\hline Subgroup 3 & Thursday & 10.2 & 10.7 & 10.8 & 11.7 & 11.8 & 11 & 11.0 & 1.6 \\
\hline Subgroup 4 & Friday & 10.3 & 11.3 & 10.7 & 10.8 & 10.2 & 11.7 & 10.8 & 1.5 \\
\hline Subgroup 5 & Saturday & 14.2 & 12.2 & 11.7 & 10.8 & 13.2 & 12.7 & 12.5 & 3.4 \\
\hline Subgroup 6 & Tuesday & 9.8 & 11.8 & 11 & 11.2 & 10 & 9.3 & 10.5 & 2.5 \\
\hline Subgroup 7 & Wednesday & 10.2 & 10.8 & 10.3 & 11.3 & 9.8 & 11.2 & 10.6 & 1.5 \\
\hline Subgroup 8 & Thursday & 10.3 & 9.2 & 10.8 & 10.2 & 11.8 & 10.5 & 10.5 & 2.6 \\
\hline Subgroup 9 & Friday & 11.7 & 11.5 & 11 & 12.2 & 10.5 & 12 & 11.5 & 1.7 \\
\hline Subgroup 10 & Saturday & 13 & 11.8 & 10.8 & 12.5 & 12.8 & 13.8 & 12.5 & 3 \\
\hline Subgroup 11 & Tuesday & 10.2 & 11.2 & 10 & 11.3 & 11 & 10.5 & 10.7 & 1.3 \\
\hline Subgroup 12 & Wednesday & 11.8 & 11.5 & 11.7 & 10.5 & 12.5 & 11 & 11.5 & 2 \\
\hline Subgroup 13 & Thursday & 11.2 & 9.5 & 12.3 & 10.7 & 10.8 & 10.3 & 10.8 & 2.8 \\
\hline Subgroup 14 & Friday & 12.2 & 12 & 10.5 & 10.3 & 11.7 & 10.5 & 11.2 & 1.9 \\
\hline Subgroup 15 & Saturday & 12.5 & 11 & 11.8 & 14.3 & 12.7 & 13.5 & 12.6 & 3.3 \\
\hline Subgroup 16 & Tuesday & 11.7 & 10.5 & 10.7 & 10.8 & 11 & 11.7 & 11.1 & 1.2 \\
\hline Subgroup 17 & Wednesday & 11.2 & 12.3 & 10.3 & 10.5 & 12.2 & 10.8 & 11.2 & 2 \\
\hline Subgroup 18 & Thursday & 10.8 & 10 & 11 & 10.5 & 10.2 & 9.8 & 10.4 & 1.2 \\
\hline Subgroup 19 & Friday & 11.7 & 10.2 & 12.3 & 11 & 10.3 & 12.8 & 11.4 & 2.6 \\
\hline Subgroup 20 & Saturday & 12.5 & 10.7 & 12 & 14.2 & 13.3 & 12.2 & $\begin{array}{c}12.5 \\
\mathrm{x} \text { double } \mathrm{bar}=11.2\end{array}$ & $\begin{array}{c}3.5 \\
\mathrm{R} \text { bar }=2.1\end{array}$ \\
\hline
\end{tabular}

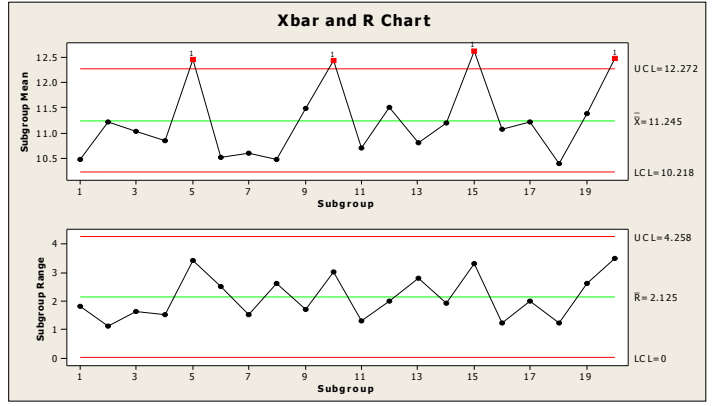

Fig. 4. $\mathrm{X}$ bar and $\mathrm{R}$ chart (20 subgroups)

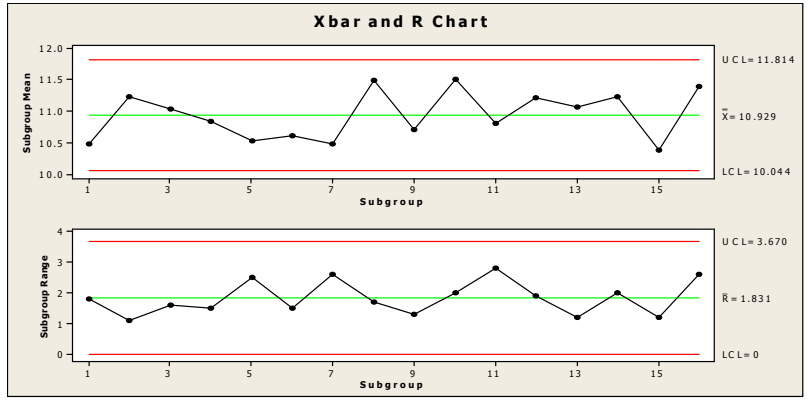

Fig. 5. $\mathrm{X}$ bar and $\mathrm{R}$ chart excluding Saturdays (16 subgroups) 
Observing $X$ bar and R chart in Fig. 4, we may say that average service time for $5^{\text {th }}, 10^{\text {th }}, 15^{\text {th }}$, and $20^{\text {th }}$ subgroup has jumped above UCL. On further investigation, it was discovered that on every Saturday concerned service executive was on leave for his personal reasons and a trainee was dealing with clients, hence it took more time on Saturdays. It was decided to effectively supervise and provide hands on training sessions to all the trainees in organization. To ensure that on other working days, service resolution time was with in control, Saturdays were excluded from data provided in Table 1 and again control limits were recalculated from remaining 16 subgroups and $\mathrm{X}$ bar and $\mathrm{R}$ chart were again plotted (Fig. 5). The process was within statistical control after excluding Saturdays with $\mathrm{X}$ double bar $=10.92$ and process capability index $\mathrm{Cpk}=-0.20$ Process was off centered and target to achieve average service resolution time of 7.5 hours has not yet achieved (Fig. 6). It means that even experienced service executives were not meeting the goal.

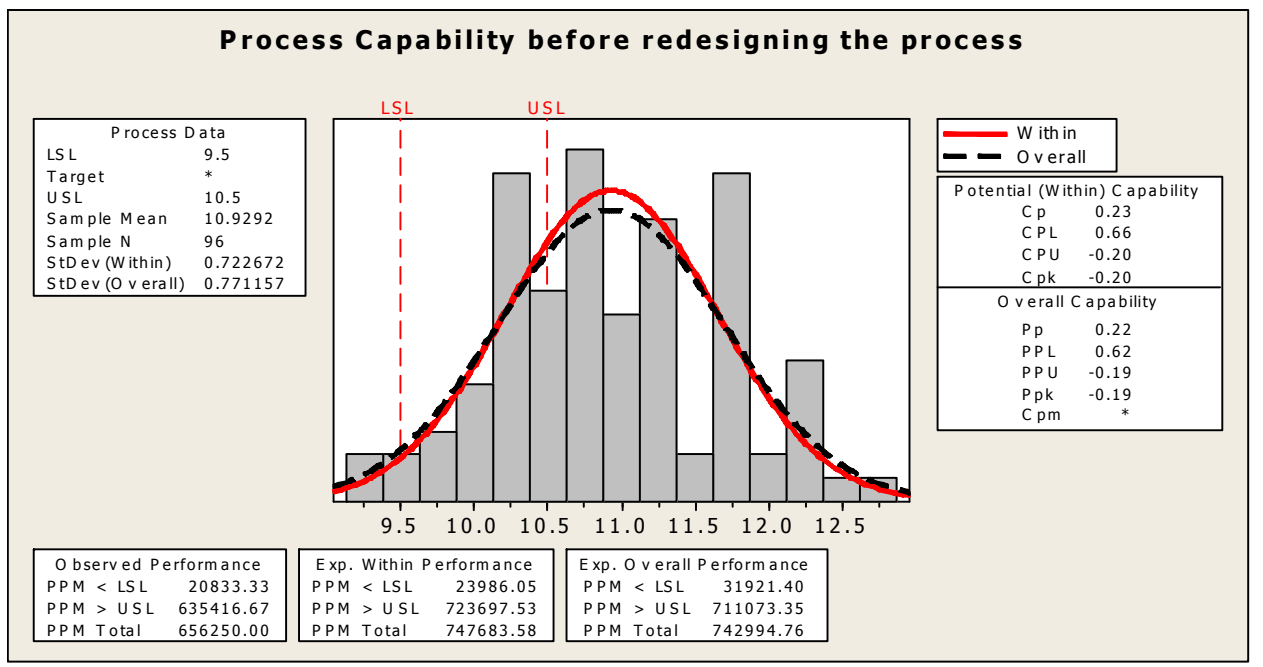

Fig. 6. Process capability of service resolution time before redesigning the process

\subsection{Improve and Control}

To further reduce service resolution time, one option was to hire more service executives and invest more resources but it was not monetarily viable option so it was decided to collect and analyze the data based on the type of service provided. Four type of services i.e. A, B, C and D take 10 hours for resolution.

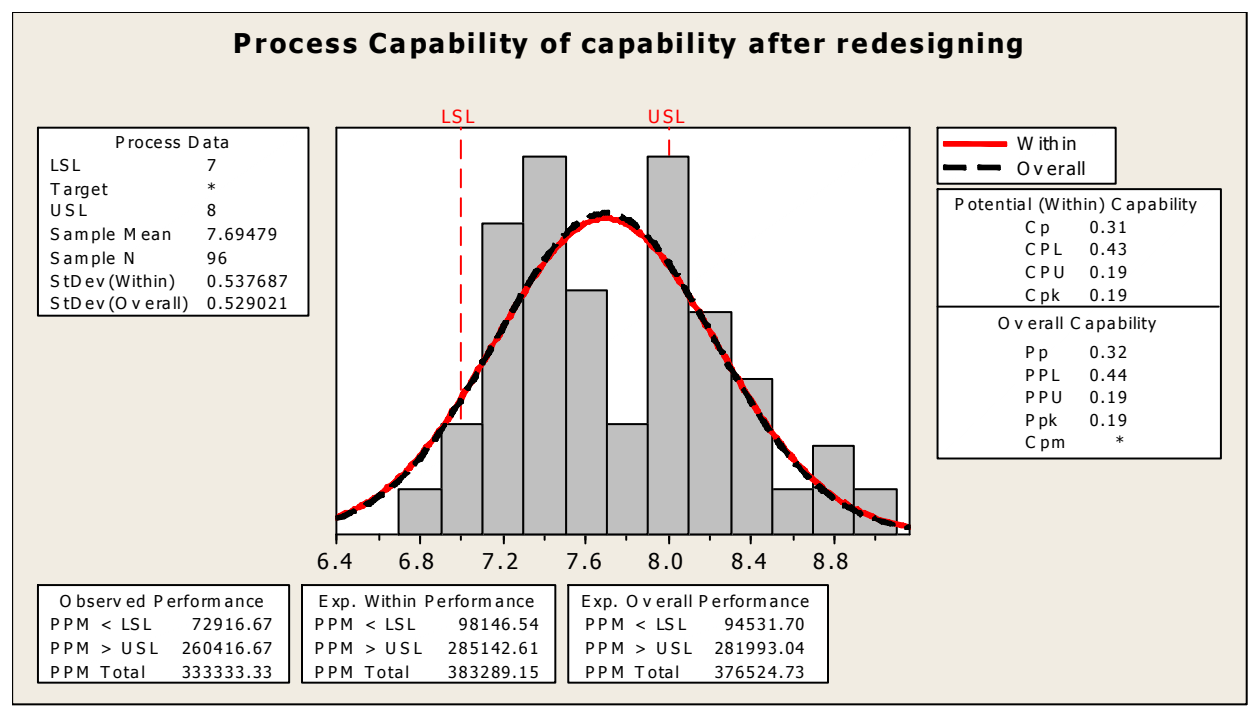

Fig. 7. Process capability of service resolution time after redesigning the process 
After sub grouping and analyzing the data based on type of service, it was discovered that service process $\mathrm{C}$ has average time of 10.7 hours. On further investigating service process $\mathrm{C}$, it was discovered that Standard Operating Procedures(SOPs) for service process $\mathrm{C}$ was not formally developed and documented hence the process was not clear and it includes many non-productive actives which resulted in increased service resolution time. It was decided to redesign the process of service $\mathrm{C}$, so that unproductive activities could be removed. After having brainstorming session with Six Sigma team, it was decided to divide service process $\mathrm{C}$ to three major phases. After dividing the process in to three phases and mean service resolution time was reduced to 7.6 hours (Fig. 7). It was further recommended to monitor the process performance regularly through process control charts.

\section{Conclusion}

Gathering data for interpreting and applying statistical methods is not the only aim of applying statistical methods. The overall aim is to enhance the understanding of the process which must be reflected in the process improvements. The full utilization of the Six Sigma can be realized only when we focus on process insight rather than process output. In the present work, it was recommended that management should delegate process ownership to people who are working on the process so that remedial action on the process can be taken without much relying on the management. In addition, it was found that training for both management \& process owners is important factor for quantum gain in process improvement. Further, selection of Six Sigma Project facilitator is equally significant for introduction and deployment of Six Sigma project within an organization. The basic philosophy of Six Sigma Methodology is to study, analyze and reduce process variations. The concept of reducing variation and using statistical signals is to improve process performance can be applied to any area. The real understanding of the process involves insight contact with actual process control situations. There is no substitute for hands on experience. The study of variation should be considered as a step towards use of statistical methods. However, it is improper to blindly use this approach. It is recommended to consult experts who have proper knowledge and practice in statistical theory as to appropriateness of other techniques. In any case, processes and procedures followed must satisfy the customer requirements and the overall aim is customer delight.

\section{Acknowledgement}

The authors would like to thank the anonymous referees for constructive comments on earlier version of this paper.

\section{References}

Antony, J. (2000). Ten key ingredients for making SPC successful in organisations. Measuring Business Excellence, 4(4), 7-10.

Antony, J. (2006). Six sigma for service processes. Business Process Management Journal, 12(2), 234248.

Banuelas, R., Tennant, C., Tuersley, I., \& Tang, S. (2006). Selection of Six Sigma projects in the UK. The TQM Magazine, 18(5), 514-527.

Besseris, G. J. (2013). Improving quality cost performance with qualimetrical methods: a case from a high-speed packaging process. The International Journal of Advanced Manufacturing Technology, 69(5-8), 1775-1789.

Chakrabarty, A., \& Kay Chuan, T. (2009). An exploratory qualitative and quantitative analysis of Six Sigma in service organizations in Singapore.Management Research News, 32(7), 614-632.

Chakraborty, A., \& Kay Chuan, T. (2013). An empirical analysis on Six Sigma implementation in service organisations. International Journal of Lean Six Sigma, 4(2), 141-170.

Chang, K. K., \& Wang, F. K. (2008). Applying Six Sigma methodology to collaborative forecasting. The International Journal of Advanced Manufacturing Technology, 39(9-10), 10331044. 
Harry, M. J., \& Schroeder, R. R. (2005). Six Sigma: The breakthrough management strategy revolutionizing the world's top corporations. Broadway Business.

Heckl, D., Moormann, J., \& Rosemann, M. (2010). Uptake and success factors of Six Sigma in the financial services industry. Business Process Management Journal, 16(3), 436-472.

Hoerl, R., \& Snee, R. D. (2012). Statistical thinking: improving business performance (Vol. 48). John Wiley \& Sons.

Kumaravadivel, A., \& Natarajan, U. (2013). Application of Six-Sigma DMAIC methodology to sandcasting process with response surface methodology. The International Journal of Advanced Manufacturing Technology, 69(5-8), 1403-1420.

Lall, V., \& Gupta, A. (2010). A tool based framework for applying Six Sigma methodology to services and transactional data. International Journal of Productivity and Quality Management, 5(4), 440451.

Leavenworth, R. S., \& Grant, E. L. (2000). Statistical quality control. Tata McGraw-Hill Education.

Levin, R. I., \& Rubin, D. (1999). Statistics for Management. Practice-Hall.

Montgomery, D., C. (2009). Introduction to Statistical Quality Control. John Wiley.

Nakhai, B., \& Neves, J. S. (2009). The challenges of Six Sigma in improving service quality. International Journal of Quality \& Reliability Management,26(7), 663-684.

Natarajan, R. N., \& Morse, J. (2009). Six Sigma in services-challenges and opportunities. International Journal of Productivity and Quality Management,4(5-6), 658-675. 